\title{
In vitro antitrypanosomal activity of the cyclodepsipeptides, cardinalisamides A-C, from the insect pathogenic fungus Cordyceps cardinalis NBRC 103832
}

\author{
Akemi Umeyama ${ }^{1}$, Koichi Takahashi ${ }^{1}$, Aleksandra Grudniewska ${ }^{1}$, Mina Shimizu ${ }^{1}$, Sayaka Hayashi ${ }^{1}$, \\ Masayuki Kato ${ }^{1}$, Yasuko Okamoto ${ }^{1}$, Midori Suenaga ${ }^{1}$, Sayaka Ban ${ }^{2}$, Toshio Kumada ${ }^{3}$, Aki Ishiyama ${ }^{4}$, \\ Masato Iwatsuki ${ }^{4}$, Kazuhiko Otoguro ${ }^{4}$, Satoshi Ōmura ${ }^{4}$ and Toshihiro Hashimoto ${ }^{1}$
}

During the search for new antitrypanosomal drug leads, three new antitrypanosomal compounds, cardinalisamides A-C (1-3), were isolated from cultures of the insect pathogenic fungus Cordyceps cardinalis NBRC 103832. Their structures were elucidated using MS analyses and extensive 2D-heteronuclear NMR. The absolute configurations of 1-3 were addressed by chemical degradation and Marfey's analysis. 1-3 showed in vitro antitrypanosomal activity against Trypanosoma brucei brucei with $\mathrm{IC}_{50}$ values of $8.56,8.65$ and $8.63 \mu \mathrm{g} \mathrm{ml}^{-1}$, respectively.

The Journal of Antibiotics (2014) 67, 163-166; doi:10.1038/ja.2013.93; published online 2 October 2013

Keywords: cardinalisamide; Cordyceps cardinalis; depsipeptides; Trypanosoma brucei brucei

\section{INTRODUCTION}

Human African trypanosomiasis, also known as sleeping sickness, is a potentially fatal parasitic disease transmitted by the bite of the tsetse fly that plagues many regions of Africa. Although the number of people being infected with the disease has declined due to better diagnosis and treatment, there were still more than 7000 new cases recorded in 2010. ${ }^{1}$ Without treatment, sleeping sickness is fatal. Morever current therapies often have unpleasant side effects.

During the course of our screening program for compounds that treat the disease, which is caused by the parasite T. brucei, we have reported on various natural products, such as microbial metabolites and plant products that exhibit potent antitrypanosomal properties. ${ }^{2-8}$ This time we focused on metabolites from cultures of Cordyceps that showed antitrypanosomal activity. Cordyceps is a fungal genus which is endopathogenic with arthropods, principally insects. This genus is proving to be a rich source of novel secondary metabolites including important compounds for pharmaceutical discovery. ${ }^{9-14}$

In 2004, Professor Joseph W. Spatafora reported on C. cardinalis, a pathogen of lepidopteran larvae, a new species from the southern Appalachian Mountains of the eastern United States and from southeastern Japan. ${ }^{15}$ C. cardinalis NBRC 103832 was isolated from single ascospores of a fruiting body occurring on a lepidopteran larva from Japan (Takatsuki, Osaka). The single stroma is ochraceous orange to red and less than $30 \mathrm{~mm}$. The anamorphic stage on PDA is
Mariannaea-like, producing imbricate conidia chains. Sequence analysis of this strain based on rDNA ITS1-5.8S-ITS2 showed 99\% similarity with C. cardinalis BCMU CC01 (AB237660).

Here, we report the isolation, structural determination and antitrypanosomal activity of three depsipeptides, cardinalisamides A-C (1-3).

\section{RESULTS}

Extraction and isolation

Laboratory cultures of C. cardinalis NBRC 103832 were grown as lawns on solid agar. The mycelia were harvested and extracted exhaustively with $\mathrm{MeOH}$. The mycelial extract was evaporated to an aqueous concentrate and successively extracted with EtOAc. The extracted material $(7.1 \mathrm{~g})$ was chromatographed on silica gel by $n$-hexane and an increasing ratio of $\mathrm{CHCl}_{3}$ and by preparative HPLC using $70-75 \% \mathrm{MeOH}$ to afford three new compounds, cardinalisamides A-C (1-3) (Figure 1).

\section{Structure elucidation}

Cardinalisamide A (1) was obtained as an oil, for which analysis based on HRFABMS data $\left(m / z \quad 687.3373\right.$ for $\left.[\mathrm{M}+\mathrm{Na}]^{+}\right)$gave the molecular formula $\mathrm{C}_{36} \mathrm{H}_{48} \mathrm{~N}_{4} \mathrm{O}_{8}$. The ${ }^{1} \mathrm{H}$ and COSY NMR spectra (Table 1) showed typical features for peptides, with an amide proton signal $\left(\delta_{\mathrm{H}} 7.49\right)$, an $N$-methyl group $\left(\delta_{\mathrm{H}} 3.27\right)$ and four $\alpha$ protons

${ }^{1}$ Faculty of Pharmaceutical Sciences, Tokushima Bunri University, Tokushima, Japan; ${ }^{2}$ Biological Resource Center (NBRC), Department of Biotechnology, National Institute of Technology and Evaluation, Chiba, Japan; ${ }^{3}$ Takeda Giken Service, Ltd, Osaka, Japan and ${ }^{4}$ Kitasato Institute for Life Sciences, Kitasato University, Tokyo, Japan 


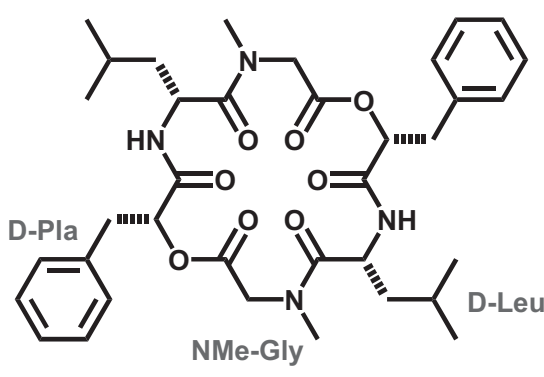

1

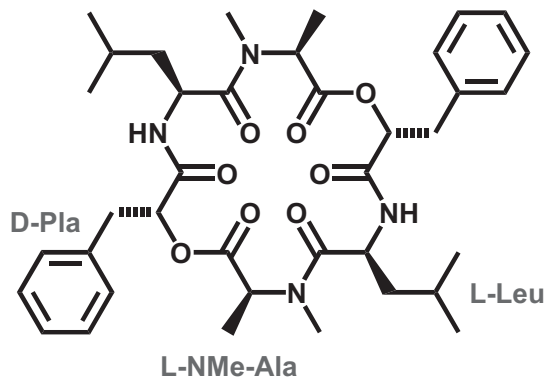

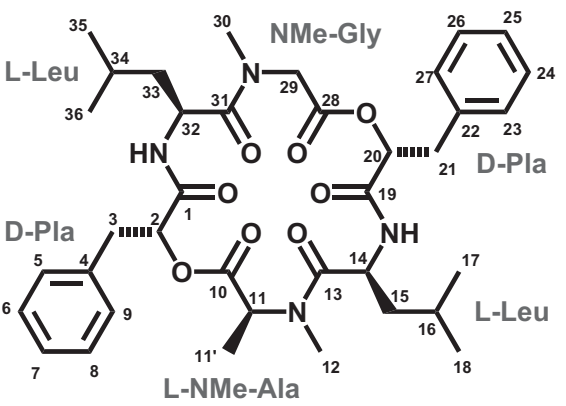

2

3

Figure 1 Structures of cardinalisamides A-C (1-3). A full color version of this figure is available at The Journal of Antibiotics journal online.

$\left(\delta_{\mathrm{H}} 5.60,5.23,4.43,3.18\right)$. The ${ }^{13} \mathrm{C}$ NMR and HSQC spectra and a DEPT experiment indicated three carbonyl carbons, six olefinic carbons, three methines, three methylenes, one downfield methyl at $37.7 \mathrm{ppm}$ and two upfield methyl signals. Based on the carbon numbers in ${ }^{13} \mathrm{C}$ NMR and the molecular formula, 1 possesses $C_{2}$ symmetry. Interpretation of COSY, HSQC and HMBC spectra allowed three distinct fragments to be constructed (Figure 2). These included two phenyllactic acid (Pla) moieties and amino acid moieties, such as two $\mathrm{N}$-methylglycines ( $\mathrm{N}$-MeGly) and two leucines (Leu). The sequence of 1 was assigned by HMBC analysis using correlations from the $\alpha$-protons or the $N$-methyl protons to the carbonyl carbon resonances. The linkage of $\mathrm{N}$-MeGly and Pla was established by HMBC correlations from the $\alpha$-proton of Pla $\left(\delta_{\mathrm{H}} 5.60\right)$ to the $N$-MeGly carbonyl $\left(\delta_{\mathrm{C}} 166.7\right)$. Connection of Leu and Pla was determined on the basis of the HMBC correlation from the $\alpha$-proton of Leu $\left(\delta_{\mathrm{H}} 5.23\right)$ to the Pla carbonyl $\left(\delta_{\mathrm{C}}\right.$ 168.4). Further, an HMBC correlation from the $N$-methyl singlet proton $\left(\mathrm{H}-12, \delta_{\mathrm{H}} 5.23\right)$ to the Leu carbonyl $\left(\delta_{\mathrm{C}} 173.9\right)$ revealed the linkage of $\mathrm{N}$-MeGly to Leu. Intense NOESY correlations from the $14-\mathrm{NH}$ to $\mathrm{H}-2^{\prime}$ and from the $\mathrm{N}$-methyl protons to $\mathrm{H}-14$ strongly suggested an alternate linkage of two amide bonds. Finally, the closure of the ring allowed the planar structure of cardinalisamide A (1) to be assigned.

The absolute configuration of Pla in $\mathbf{1}$ was determined as D by chiral HPLC analyses using direct comparison with authentic specimens. The absolute configuration of the amino acid (Leu) in $\mathbf{1}$ was assigned by application of Marfey's method. ${ }^{16-18}$ Acid hydrolysis of the hydrogenated product of 1 yielded the expected free amino acids, which were derivatized using FDAA (Marfey's reagent, 1-fluoro-2, 4-dinitrophenyl-5-L-alanine amide) and analyzed by LC/MS by comparing the chromatograms with those derivatives of authentic specimens. Retention times (in min) of the FDAA derivatives of Leu were L-Leu (16.6) and D-Leu (17.8). The amino acids (Leu $\times 2)$ in $\mathbf{1}$, which had a retention time of 17.4 , thus have the D-configuration.

The same extract afforded cardinalisamide B (2) as an oil, which was assigned the molecular formula $\mathrm{C}_{37} \mathrm{H}_{50} \mathrm{~N}_{4} \mathrm{O}_{8}$ based on HRFABMS data $\left(\mathrm{m} / z 701.3534\right.$ for $\left.[\mathrm{M}+\mathrm{Na}]^{+}\right)$. This indicated that $\mathbf{2}$ differed from $\mathbf{1}$ by the presence of a $\mathrm{CH}_{2}$ unit. The ${ }^{1} \mathrm{H}$ and ${ }^{13} \mathrm{C}$ NMR spectra of $\mathbf{2}$ (Table 1) were similar to those of $\mathbf{1}$ except for $C_{2}$ symmetry in $\mathbf{1}$. COSY, HSQC and $\mathrm{HMBC}$ spectral data allowed the assignment of one $\mathrm{N}$-MeGly, one $\mathrm{N}$-methylalanine ( $\mathrm{N}$-MeAla), two Leu and two Pla. The sequence of 2 was also determined by HMBC spectra and NOE correlations between $\mathrm{H}-12$ and $\mathrm{H}-14,14-\mathrm{NH}$ and $\mathrm{H}-20, \mathrm{H}-30$ and $\mathrm{H}-32$ and $32 \mathrm{NH}$ and $\mathrm{H}-2$. The absolute configuration of the amino acids and the Pla was deduced as follows. Acid hydrolysis and FDAA derivatization of Leu (16.7) revealed L-Leu by LC-MS analysis. The absolute configuration of $N$-MeAla was determined using the advanced Marfey method (using an FDLA derivative) because the retention times of the FDAA derivatives of D- and L-N-MeAla were very similar. FDLA derivatization of N-MeAla (9.2) revealed L-N-MeAla by LC-MS analysis. The configuration of the Pla was determined to be $\mathrm{D}$, based on comparison of the retention time of the Pla from the hydrolysate with those of authentic specimens of D- and L- Pla on a chiral HPLC column.

Cardinalisamide C (3) was obtained as an oil that showed an $[\mathrm{M}+\mathrm{Na}]^{+}$peak at $\mathrm{m} / z$ 715.3712, for a molecular formula of $\mathrm{C}_{38} \mathrm{H}_{52} \mathrm{~N}_{4} \mathrm{O}_{8}$ by HRFABMS, which differs from that of 2 by the presence of a $\mathrm{CH}_{2}$ unit. The ${ }^{1} \mathrm{H}$ and ${ }^{13} \mathrm{C}$ NMR spectra of 3 (Table 1) were similar to those of 2.3 possessed $C_{2}$ symmetry based on its carbon numbers in the ${ }^{13} \mathrm{C}$ NMR and the molecular formula. The difference in $\mathbf{3}$ was the replacement of an $\mathrm{N}$-MeGly unit in $\mathbf{2}$ with an $\mathrm{N}$-MeAla unit. Analysis of ${ }^{1} \mathrm{H}$ NMR, ${ }^{13} \mathrm{C}$ NMR, HSQC, COSY and HMBC spectra revealed the presence of two N-MeAla, two Leu and two Pla moieties. Finally, the sequence of 3 was established by HMBC correlations and supported by observed NOE enhancements. The absolute configurations of the amino acid units of $\mathbf{3}$ were determined in an identical fashion to that used for 2. Acid hydrolysis and L-FDAA derivatization of Leu (16.6) and L-FDLA derivatization of N-MeAla (9.2) revealed L-N-MeAla and L-Leu by LC-MS analysis, respectively. Finally, chiral-phase HPLC revealed L-Pla, completing the absolute configurational assignment of cardinalisamide C (3). 
Table 1 NMR data for cardinalisamides $\mathrm{A}(1)-\mathrm{C}(3)$ in $\mathrm{CDCl}_{3}$

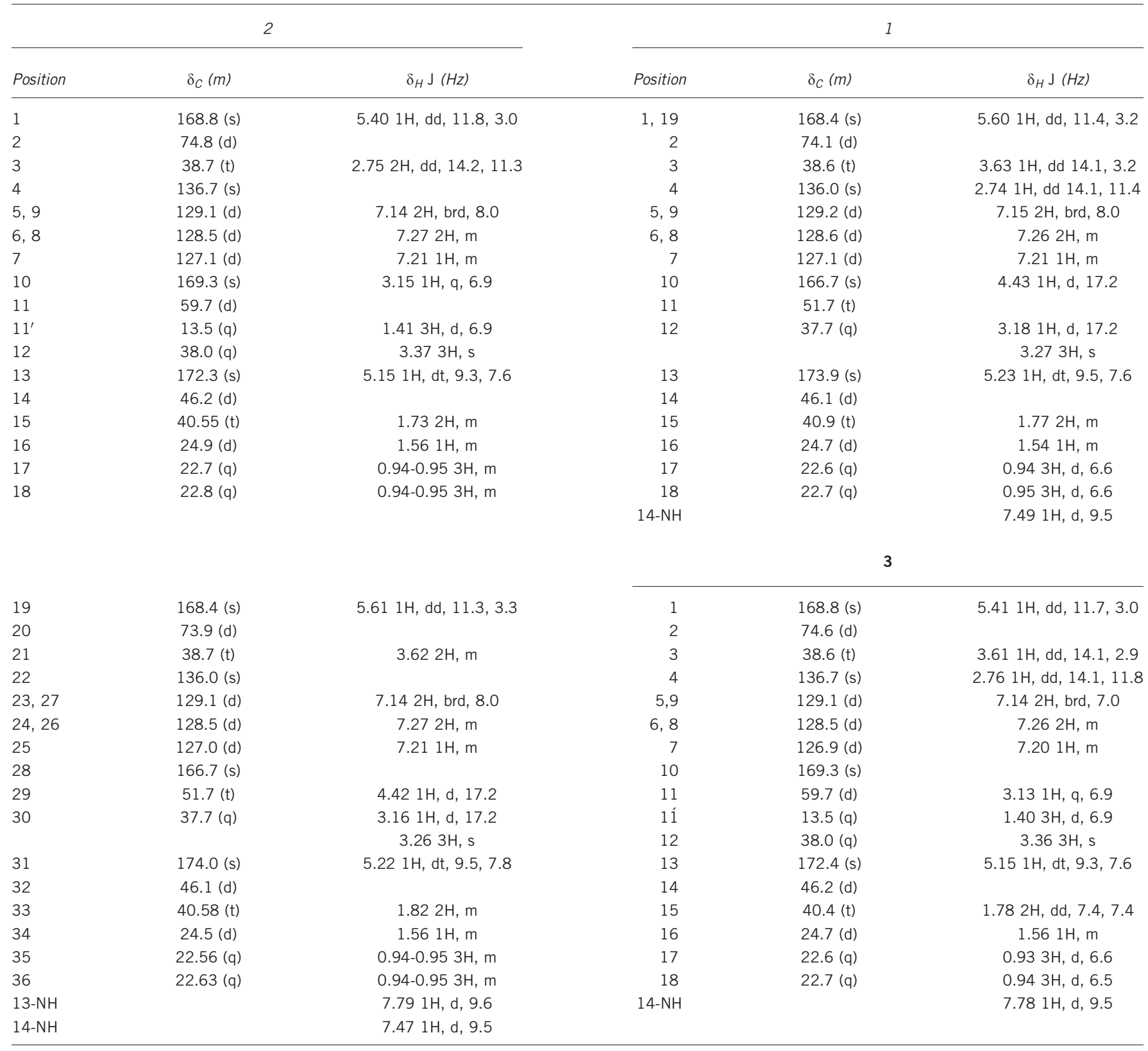

1 and $\mathbf{3}$ possessed C2 symmetry.

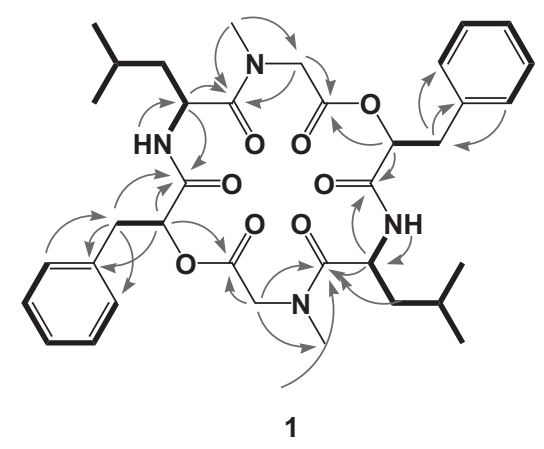

Figure 2 COSY and selected $\mathrm{HMBC}$ correlations for $\mathbf{1}$, indicating the sequence of six residues. A full color version of this figure is available at The Journal of Antibiotics journal online.

\section{Biological activity}

Cardinalisamides A-C (1-3) showed in vitro antitrypanosomal activity against $T$. brucei brucei with $\mathrm{IC}_{50}$ values of $8.56,8.65$ and $8.63 \mu \mathrm{g} \mathrm{ml}^{-1}$, and cytotoxicity against normal human diploid fibroblasts (MRC-5 cells) with $\mathrm{IC}_{50}$ values of $18.48,14.00$ and $23.84 \mu \mathrm{g} \mathrm{ml}^{-1}$, respectively.

\section{EXPERIMENTAL SECTION}

\section{General experimental procedures}

Optical rotations were recorded on a JASCO P-1030 polarimeter. IR spectra were measured on a Shimazu FTIR-8400S instrument. NMR spectra were obtained on a Varian UNITY 600 NMR spectrometer. The chemical shifts are given in $\delta(\mathrm{ppm})$, and coupling constants are reported in Hz. HRMS spectra were obtained on a JEOL JMS-700 instrument. Kieselgel 60 (230-400 mesh, Merk) was used for column chromatography, and silica gel 60 F-254 (Merk) 
for TLC. HPLC was performed on a JASCO-PU 1580 instrument with a COSMOSIL C18 P-MS II $(250 \times 20 \mathrm{~mm})$.

\section{Fungal material, extraction and isolation}

The fungus C. cardinalis NBRC 103832 was identified by Dr Ban of the Nite Biological Resource Center (NBRC). A voucher specimen (C. cardinalis NBRC 103832) is deposited at the NBRC ulture Collection. C. cardinalis NBRC 103832 was cultured for 2 weeks at $25^{\circ} \mathrm{C}$ in potato sucrose medium (101 culture). Mycelia were separated from the broth by filtration and subsequently extracted twice with $\mathrm{MeOH}$ to yield $16.3 \mathrm{~g}$ of a crude extract in an ultrasonic bath for $60 \mathrm{~min}$. The extract was concentrated and the resulting residue was extracted with EtOAc $(500 \mathrm{ml} \times 3)$. The EtOAc-soluble portion $(7.1 \mathrm{~g})$ was repeatedly subjected to silica gel flash column chromatography (using increasing concentrations of $\mathrm{CHCl}_{3}$ and $\mathrm{MeOH}$ in $n$-hexane as eluent). Further purification was carried out by repeated preparative HPLC on an ODS C-18 column, using $\mathrm{MeOH}$ and $\mathrm{H}_{2} \mathrm{O}$ as a solvent system to afford 1 $(12.6 \mathrm{mg}), 2(53.6 \mathrm{mg})$ and $3(34.9 \mathrm{mg})$.

Cardinalisamide A (1): pale yellow oil; $[\alpha]_{\mathrm{D}}{ }^{23}-46.6^{\circ}$ ( $c 0.33$, MeOH); FT-IR (film) $\mathrm{cm}^{-1}: 3299,1751,1672,1636,1626$; HRFABMS $\mathrm{m} / z:[\mathrm{M}+\mathrm{Na}]^{+}$ 687.3373, calcd for $\mathrm{C}_{36} \mathrm{H}_{48} \mathrm{~N}_{4} \mathrm{O}_{8} \mathrm{Na}$ 687.3370; COSY and HMBC data see Figure 1.; Selected NOESY (H/H) 12/14, 14-NH/20.

Cardinalisamide B (2): pale yellow oil; $[\alpha]_{\mathrm{D}}^{23}-86.8^{\circ}(c 0.59, \mathrm{MeOH})$; FT-IR (film) $\mathrm{cm}^{-1}$ : 3279, 1753, 1672, 1636, 1628; HRFABMS $\mathrm{m} / \mathrm{z}:[\mathrm{M}+\mathrm{Na}]^{+}$ 701.3534, calcd for $\mathrm{C}_{37} \mathrm{H}_{50} \mathrm{~N}_{4} \mathrm{O}_{8} \mathrm{Na} 701.3526$; COSY $(\mathrm{H} / \mathrm{H}) 2 / 3,5 / 6,6 / 7,7 / 8$, $8 / 9,11 / 11^{\prime}, 14 \mathrm{NH} / 14,14 / 15,15 / 16,16 / 17,16 / 18,20 / 21,23 / 24,24 / 25,25 / 26$ 26/27, 32NH/32, 32/33, 33/34, 34/35, 34/36; HMBC (H/C) 2/1, 2/10, 3/5, 3/4, $3 / 9,5 / 3,9 / 3,11 / 10,11 / 12,11 / 13,12 / 11,12 / 13,13 / 12,14 / 13,14 / 19,20 / 19,20 /$ 28, 21/22, 21/23, 21/27, 23/21, 27/21, 29/28, 29/30, 29/31, 30/29, 30/31, 32/31 $32 / 1,32 \mathrm{NH} / 1$; Selected NOESY (H/H) 12/14, 14-NH/20, 30/32, 32-NH/2.

Cardinalisamide C (3): pale yellow oil; $[\alpha]_{\mathrm{D}}^{23}-105.4^{\circ}($ c $0.84, \mathrm{MeOH})$; FT-IR (film) $\mathrm{cm}^{-1}$ : 3275, 1751, 1672, 1659, 1629; HRFABMS $m / z:[\mathrm{M}+\mathrm{Na}]^{+}$ 715.3712, calcd for $\mathrm{C}_{38} \mathrm{H}_{52} \mathrm{~N}_{4} \mathrm{O}_{8} \mathrm{Na}$ 715.3683; COSY (H/H) 2/3, 5/6, 6/7, 7/8, $8 / 9,11 / 11^{\prime}, 14 \mathrm{NH} / 14,14 / 15,15 / 16,16 / 17,16 / 18$; HMBC (H/C) 2/1, 2/4, 3/1, $3 / 4,3 / 5,5 / 6,5 / 7,7 / 5,11 / 10,11 / 12,11 / 13,11^{\prime} / 10,12 / 11,12 / 13,14 / 13,14 / 1,15 /$ 13; Selected NOESY $(\mathrm{H} / \mathrm{H}) 5$ or $9 / 11,12 / 14,14-\mathrm{NH} / 2^{\prime}$.

\section{Acid hydrolysis of 1-3}

A tube containing $1-3(1.2 \mathrm{mg})$ and $6 \mathrm{M} \mathrm{HCl}(1 \mathrm{ml})$ was kept at $110^{\circ} \mathrm{C}$ for $21 \mathrm{~h}$. This solution was evaporated to dryness under vacuum to give the hydrolysate of $1-3$, respectively.

\section{Absolute configuration of Pla in 1-3}

The hydrolysate was dissolved in $1 \mathrm{ml}$ of water, with $5 \mu \mathrm{l}$ of this solution used for one analysis. HPLC analysis was performed on DAICEL OD-RH chiral column $(250 \times 4.6,5 \mu \mathrm{m}$; solvents: (A) $\mathrm{pH} 2$ formic acid + water, (B) $20 \%$ $\mathrm{MeCN} ; 0.5 \mathrm{ml}$ per $\left.\min ; 25^{\circ} \mathrm{C}\right)$. The configuration was determined by co-injection with L-Pla (tR 8.8) and D-Pla (tR 8.5).

\section{Preparation and analysis of Marfey derivatives}

1-3 $(0.2 \mathrm{mg})$ was hydrolyzed by heating in $\mathrm{HCl}(6 \mathrm{M} ; 1 \mathrm{ml})$ at $110^{\circ} \mathrm{C}$ for $14 \mathrm{~h}$ After cooling, the solution was lyophilized and redissolved in $0.1 \mathrm{~N} \mathrm{HCl}$ $(100 \mu \mathrm{l}$ ). To the acid hydrolysate solution (or to $50 \mu \mathrm{l}$ of a $50 \mathrm{~mm}$ solution of the respective amino acid) was added a $1 \%(\mathrm{w} / \mathrm{v})$ solution $(100 \mu \mathrm{l})$ of $\mathrm{FDAA}^{9}$ or FDLA ${ }^{10}$ in acetone. After addition of $\mathrm{NaHCO}_{3}$ solution $(1 \mathrm{M} ; 20 \mu \mathrm{l})$ the mixture was incubated for $1 \mathrm{~h}$ at $40^{\circ} \mathrm{C}$. The reaction was stopped by addition of $\mathrm{HCl}(1 \mathrm{M} ; 20 \mu \mathrm{l})$, the solvents were evaporated to dryness, and the residue was redissolved in acetonitrile $(100 \mu \mathrm{l})$. An aliquot of this solution $(20 \mu \mathrm{l})$ was analyzed by HPLC (COSMOSIL 5C18 MS-II, $150 \times 4.6,5 \mu \mathrm{m}$; solvents: (A) $0.05 \%$ TFA water, (B) $0.05 \%$ TFA MeCN; linear gradient of from $10 \% \mathrm{MeCN}$ to $70 \% \mathrm{MeCN}$ in $15 \mathrm{~min}$ and isocratic at $70 \% \mathrm{MeCN}$ for the next $10 \mathrm{~min}$. $0.5 \mathrm{ml} \mathrm{min}^{-1} ; 25^{\circ} \mathrm{C}$ ). Retention times ( $\mathrm{min}$ ) of the FDAA derivatives of Leu were as follows: L-Leu (16.6) and D-Leu (17.8).

(COSMOSIL 5C18 MS-II, $150 \times 4.6,5 \mu \mathrm{m}$; solvents: (A) water $+\mathrm{pH} 2$ formic acid, (B) $\mathrm{MeCN} ; 40 \% \mathrm{~B} ; 0.5 \mathrm{ml} \mathrm{min}^{-1} ; 25^{\circ} \mathrm{C}$ ). Retention times (min) of the FDLA derivatives of N-MeAla were as follows: L-N-MeAla (9.2) and D-N-MeAla (11.7)

\section{Trypanosome}

The bloodstream forms of T. $b$. brucei strain GUTat 3.1 parasites were used for experimentation as described previously. ${ }^{19}$

\section{In vitro assay}

The in vitro antitrypanosomal assays using $T b$ brucei strain GUTat 3.1 have been described previously. ${ }^{19}$ In brief, $95 \mu$ l of parasite suspension was incubated with $5 \mu \mathrm{l}$ of drug solution for $72 \mathrm{~h}$ and Alamar Blue was used for parasite survival determination to calculate $\mathrm{IC}_{50}$ values.

Cytotoxicity assay against human diploid embryonic cell line MRC-5 was carried out as previously described. ${ }^{20}$

\section{ACKNOWLEDGEMENTS}

We are indebted to Dr M Tanaka for measurements of the $600 \mathrm{MHz}$ NMR spectra, Faculty of Pharmaceutical Sciences of this University. This work was supported by a grant from MEXT (the Ministry of Education, Culture, Sports, Science and Technology of Japan)-Senryaku project (No. S0891078).

1 WHO. Home page of World Health Organization. http://www.who.int/trypanosomiasis african/en/ (2013)

2 Toriizuka, Y. et al. New lycorine-type alkaloid from Lycoris traubii and evaluation of antitrypanosomal and antimalarial activities of lycorine derivatives. Bioorg. Med. Chem. 16, 10182-10189 (2008).

3 Abdel-Sattar, E. et al. Acylated pregnane glycosides from Caralluma tuberculata and their antiparasitic activity. Phytochemistry 69, 2180-2186 (2008).

4 Ishiyama, A. et al. In vitro and in vivo antitrypanosomal activities of three peptide antibiotics: leucinostatin A and B, alamethicin I and tsushimycin. J. Antibiot. 62, 303-308 (2009)

5 Iwatsuki, M. et al. Antitrypanosomal peptaibiotics, trichosporins B-VIla and B-VIIb, produced by Trichoderma polysporum FKI-4452. J. Antibiot. 63, 331-333 (2010).

6 Hashida, J. et al. Pyrenocine I, a new pyrenocine analog produced by Paecilomyces sp. FKI-3573. J. Antibiot. 63, 559-561 (2010).

7 Niitsuma, M. et al. Sinefungin VA and dehydrosinefungin V, new antitrypanosoma antibiotics produced by Streptomyces sp. K05-0178. J. Antibiot. 63, 673-679 (2010).

8 Inahashi, Y. et al. Spoxazomicins A-C, novel antitrypanosomal alkaloids produced by an endophytic actinomycete, Streptosporangium oxazolinicum K07-0460T. J. Antibiot 64, 303-307 (2011)

9 Lin, X., Chen, J. \& Zheng, S. A medicated tea for health protection comprising Chinese caterpillar fungus, and preparation method thereof, from Faming Zhuanli Shenqing, CN 1155384 A 19970730 (1997).

10 Isaka, M., Tanticharoen, M., Kongsaeree, P. \& Thebtaranonth, Y. Structures of Cordypyridones A-D, antimalarial N-Hydroxy- and N-Methoxy-2-pyridones from the insect pathogenic fungus Cordyceps nipponica. J. Org. Chem. 66, 4803-4808 (2001).

11 Rukachaisirikul, V., Pramjit, S., Pakawatchai, C., Isaka, M. \& Supothina, S. 10-membered macrolides from the insect pathogenic fungus Cordyceps militaris BCC 2816. J. Nat. Prod. 67, 1953-1955 (2004).

12 Isaka, M., Kittakoop, P., Kirtikara, K., Hywel-Jones, N. L. \& Thebtaranonth, Y. Bioactive substances from insect pathogenic fungi. Acc. Chem. Res. 38, 813-823 (2005).

13 Russell, R. \& Paterson, M. Cordyceps - A traditional Chinese medicine and another fungal therapeutic biofactory? Phytochemistry 69, 1469-1495 (2008)

14 Haritakun, R., Sappan, M., Suvannakad, R., Tasanathai, K. \& Isaka, M. An antimycobacterial cyclodepsipeptide from the entomopathogenic fungus Ophiocordyceps communis BCC 16475. J. Nat. Prod. 73, 75-78 (2010).

15 Sung, G. H. \& Spatafora, J. W. Cordyceps cardinalis sp. Nov., a new species of Cordyceps with an east Asian-eastern North America distribution. Mycologia 96, 658-666 (2004).

16 Marfey, P. Determination of D-amino acids. II. Use of a bifunctional reagent, 1,5 difluoro-2,4-dinitrobenzene. Carlsberg. Res. Commun. 49, 591-596 (1984).

17 Fujii, K. et al. A non-empirical method using LC/MS for determination of the absolute configuration of constituent amino acids in a peptide: elucidation of limitations of Marfey's method and of its separation mechanism. Anal. Chem. 69, 3346-3352 (1997).

18 Fujii, K., Ikai, Y., Oka, H., Suzuki, M. \& Harada, K. A nonempirical method using LC MS for determination of the absolute configuration of constituent amino acids in a peptide: combination of Marfey's method with mass spectrometry and its practical application. Anal. Chem. 69, 5146-5151 (1997).

19 Otoguro, K. et al. Selective and potent in vitro antitrypanosomal activities of 10 microbial metabolites. J. Antibiot. 61, 372-378 (2008)

20 Otoguro, K. et al. Potent antimalarial activities of polyether antibiotic, X-206. J. Antibiot. 54, 658-663 (2001). 